\title{
Prone Positioning in Patients With COVID-19: Analysis of Multicenter Registry Data and Meta-analysis of Aggregate Data
}

\author{
ANASTASIOS KOLLIAS*, KONSTANTINOS G. KYRIAKOULIS*, VASILIKI RAPTI, \\ IOANNIS P. TRONTZAS, THOMAS NITSOTOLIS, KONSTANTINOS SYRIGOS, \\ GARYPHALLIA POULAKOU and THE PROPCOR CONSORTIUM-7 INVESTIGATORS \\ Third Department of Medicine, National and Kapodistrian University of Athens, \\ School of Medicine, Sotiria Hospital, Athens, Greece
}

\begin{abstract}
Background/Aim: Evidence suggests a beneficial effect of prone positioning (PP) in COVID-19. Materials and Methods: Meta-analysis of individual (7 investigators' groups) and aggregate data (PubMed/EMBASE) regarding the impact of $P P$ on the ratio of arterial partial pressure of oxygen to fraction of inspired oxygen $\left(\mathrm{PO}_{2} / \mathrm{FiO}_{2}\right)$ in patients with COVID-19. Results: Among 121 patients (mean age $\pm S D$ $59.1 \pm 10.7$ years, $55 \%$ males, $57 \%$ intubated) the mean postversus pre- $\mathrm{PP} \mathrm{PO}_{2} / \mathrm{FiO}_{2}$ difference was: (i) $50.4 \pm 64.3 \mathrm{mmHg}$, $p<0.01$, (ii) similar in awake $(58.7 \pm 72.1 \mathrm{mmHg})$ versus intubated patients $(44.1 \pm 57.5 \mathrm{mmHg}, p=N S)$, (iii) inversely correlated with body mass index $(r=-0.43, p<0.01)$. Metaanalysis of 23 studies ( $n=547$, weighted age $58.3 \pm 4.1,73 \%$ males, 59\% intubated) showed a pooled $\mathrm{PO}_{2} / \mathrm{FiO}_{2}$ difference
\end{abstract}

This article is freely accessible online.

*These Authors contributed equally to this study.

Collaborators: OSAMA ABOU-ARAB, BERNARD ALLAOUCHICHE, ALFREDO J. ASTUA, KALOMOIRA ATHANASIOU, FRANCESCO BARONE-ADESI, DAMIEN BASILLE, CHRISTOPHE BEYLS, EMMANUEL BOSELLI, ATHINA DAPERGOLA, LUCA GRILLENZONI, PRERANA JAIN, ELENI KAKALOU, SMARAGDI KALOMOIRI, STANISLAS LEDOCHOWSKI, WEIHUA LU, ANDREW J. MICHAELS, ELI K. MICHAELS, ALBA RIPOLL-GALLARDO, PRABHANJAN SINGH, TAO WANG, QIANCHENG XU

Correspondence to: Anastasios Kollias, MD, Ph.D., National and Kapodistrian University of Athens, School of Medicine, Third Department of Medicine, Sotiria Hospital, 152 Mesogion Avenue, Athens 11527, Greece. Tel: +30 2107763117, e-mail: taskollias@gmail.com

Key Words: COVID-19, meta-analysis, oxygenation, prone position, respiratory distress. of 61.8 [95\% confidence intervals=49.9-73.6] $\mathrm{mmHg}$. Metaregression analysis revealed no associations with baseline demographics, the time in PP before assessment, and the risk of bias of the studies. Conclusion: PP seems to improve oxygenation of patients with COVID-19.

Prone positioning has been shown to improve oxygenation in patients with acute respiratory distress syndrome (ARDS) through effects on the mechanics and physiology of gas exchange (1-3). The available evidence suggests a survival benefit in selected patients mainly with early application of prolonged prone-positioning sessions $(2,3)$.

Severe coronavirus disease 2019 (COVID-19) can lead to ARDS, which is characterized by high mortality (4). Preliminary evidence suggests that prone positioning might benefit oxygenation of awake patients with severe COVID-19 $(5,6)$. However, the effect of prone positioning in COVID-19related ARDS is still unclear. This study aimed to characterize the effect of prone positioning on oxygenation in patients with COVID-19 and ARDS, including patients in the awake status, as well as mechanically ventilated, by meta-analyzing individual and aggregate data.

\section{Materials and Methods}

Analysis of raw data. Seven groups of investigators (PROne Positioning in COvid-19 Research Consortium-7) provided raw data regarding the effect of prone positioning on the ratio of arterial partial pressure of oxygen to fraction of inspired oxygen $\left(\mathrm{PO}_{2} / \mathrm{FiO}_{2}\right)$ values in hospitalized patients with COVID-19 (7-12). The summary characteristics and methodology of these studies are shown in Table I. Four studies included awake patients with COVID-19 (present study, $8,11,12$ ). In case of multiple sessions of prone positioning per patient and respective comparisons of $\mathrm{PO}_{2} / \mathrm{FiO}_{2}$ values, the average $\mathrm{PO}_{2} / \mathrm{FiO}$ difference per patient was used in the main analysis. All studies were approved by Scientific and Ethics Committees with details included in the respective publications (7-12). The current study was approved by the Ethics Committee of the Sotiria Hospital, Athens, Greece. 
in vivo $36: 361-370(2022)$

Table I. Main characteristics of the crossover studies examining the effect of prone positioning on $\mathrm{PO}_{2} / \mathrm{FiO}_{2}$ ratio (gray-highlighted the ones that contributed to the PROne Positioning in COvid-19 Research Consortium-7)

\begin{tabular}{|c|c|c|c|c|c|c|c|}
\hline Study & $\begin{array}{l}\text { Setting, } \\
\text { Country }\end{array}$ & $\mathrm{N}$ & $\begin{array}{l}\text { ICU } \\
(\%)\end{array}$ & $\begin{array}{c}\text { Age, years } \\
(\text { mean } \pm S D)\end{array}$ & $\begin{array}{c}\text { Oxygen } \\
\text { delivery } \\
\text { mode }\end{array}$ & $\begin{array}{l}\text { Time of } \\
\text { prone positioning } \\
\text { session before } \\
\text { assessment } \\
\text { (min) }\end{array}$ & $\begin{array}{l}\text { Post minus } \\
\text { pre prone } \\
\mathrm{PO}_{2} / \mathrm{FiO}_{2} \\
\text { difference } \\
\text { (mean } \pm \mathrm{SD} \text { ) }\end{array}$ \\
\hline
\end{tabular}

\begin{tabular}{|c|c|c|c|c|c|c|c|}
\hline Present study & GW, Greece & 14 & 0 & $57 \pm 8$ & Supplemental oxygen & 283 & $112 \pm 122$ \\
\hline Avdeev et al. (21) & CCU, Russia & 22 & 0 & $50 \pm 18$ & Supplemental oxygen, NIMV & 180 & $37 \pm 21$ \\
\hline Astua et al. (7) & ICU, USA & 29 & 100 & $59 \pm 9$ & Endotracheal intubation & 900 & $31 \pm 55$ \\
\hline Clarke et al. (22) & ICU, Ireland & 20 & 100 & $53 \pm 12$ & Endotracheal intubation & NR & $151 \pm 102$ \\
\hline Khullar et al. (23) & ICU, USA & 23 & 100 & $54 \pm 13$ & Endotracheal intubation & NR & $118 \pm 75$ \\
\hline Perier et al. (24) & ICU, France & 14 & 100 & NR & Endotracheal intubation & NR & $53 \pm 41$ \\
\hline Singh et al. (8) & HDU, India & 15 & 0 & $52 \pm 12$ & Supplemental oxygen, NIMV & NR & $33 \pm 21$ \\
\hline Gleissman et al. (25) & ICU, Sweden & 44 & 100 & $61 \pm 13$ & Endotracheal intubation & 910 & $55 \pm 70$ \\
\hline Boselli et al. (9) & ICU, France & 15 & 100 & $62 \pm 10$ & Endotracheal intubation & NR & $94 \pm 58$ \\
\hline Weiss et al. (26) & ICU, USA & 42 & 100 & $60 \pm 13$ & Endotracheal intubation & 60 & $77 \pm 73$ \\
\hline Bagate et al. (27) & ICU, France & 10 & 100 & $61 \pm 7$ & Endotracheal intubation & NR & $49 \pm 49$ \\
\hline Abou-Arab et al. (10) & ICU, France & 25 & 100 & $61 \pm 6$ & Endotracheal intubation & 960 & $31 \pm 53$ \\
\hline Burton-Papp et al. (28) & ICU, UK & 20 & 100 & $53 \pm 8$ & NIMV & NR & $29 \pm 23$ \\
\hline Paternoster et al. (29) & HDU, Italy & 11 & 0 & $62 \pm 10$ & NIMV, helmet CPAP & NR & $137 \pm 95$ \\
\hline Berrill et al. (30) & ICU, UK & 34 & 100 & $59 \pm 11$ & Endotracheal intubation & 90 & $44 \pm 55$ \\
\hline Winearls et al. (31) & HDU, UK & 24 & 0 & $62 \pm 13$ & NIMV & 15 & $51 \pm 71$ \\
\hline Taboada et al. (32) & GW, Spain & 29 & 0 & $64 \pm 12$ & Supplemental oxygen & 60 & $46 \pm 85$ \\
\hline Solverson et al. (33) & GW, ICU, Canada & 17 & 71 & $55 \pm 13$ & Supplemental oxygen, HFNC & NR & $27 \pm 23$ \\
\hline Ripoll-Gallardo et al. (11) & GW, Italy & 13 & 0 & $66 \pm 8$ & NIMV, helmet CPAP & NR & $51 \pm 59$ \\
\hline Coppo et al. (34) & ER, GW, HDU, Italy & 56 & 0 & $57 \pm 7$ & Supplemental oxygen, NIMV & 10 & $105 \pm 118$ \\
\hline Golestani-Eraghi et al. (35) & ICU, Iran & 10 & 100 & NR & NIMV & NR & $21 \pm 4$ \\
\hline Lemyze et al. (36) & ICU, France & 33 & 100 & NR & Endotracheal intubation & NR & $162 \pm 68$ \\
\hline $\mathrm{Xu}$ et al. (12) & Hospitalized, China & 10 & 100 & $50 \pm 9$ & HFNC & 300 & $34 \pm 16$ \\
\hline Ziehr et al. (37) & ICU, USA & 31 & 100 & NR & Endotracheal intubation & NR & $84 \pm 82$ \\
\hline
\end{tabular}

CCU: COVID-19 care unit; COVID-19: coronavirus disease 2019; CPAP, continuous positive airway pressure; ED: emergency department; GW: general ward; HDU, high dependency unit; HFNC: high flow nasal cannula; ICU: intensive care unit; NIMV: non-invasive mechanical ventilation; NR: not reported; $\mathrm{PO}_{2} / \mathrm{FiO}_{2}$ : ratio of arterial partial pressure of oxygen to fraction of inspired oxygen.

Meta-analysis of aggregate data.

Search strategy. A systematic review and meta-analysis was performed according to PRISMA Guidelines (13). A systematic search at PubMed and EMBASE databases was performed to identify eligible articles until January 26, 2021 using the following algorithm: (“coronavirus 2019" OR "2019-nCoV" OR "SARS-CoV2" OR "COVID-19" OR COVID OR COVID19) AND ("prone position*" OR "proning"). Articles were also identified from reference lists of relevant papers and handsearch. The study selection was performed independently by three investigators (KGK, VR, IPT). Disagreements were resolved by consensus with a senior author (AK).

Selection criteria and data extraction. Eligible studies were fulltext peer-reviewed articles in English that included at least 10 hospitalized patients with COVID-19 and reported results regarding the effect of prone positioning on oxygenation and outcome. The primary endpoint included the difference in $\mathrm{PO}_{2} / \mathrm{FiO}_{2}$ values derived from crossover studies (same patients pre- and post- prone positioning). The secondary outcome included the adjusted odds/hazard ratio for intubation or death derived from parallel arm studies.
Data extraction and risk of bias assessment. Authors of the included studies were contacted by email to obtain additional details not reported in the published paper (i.e., mean and SD of difference regarding the variable of interest). Three investigators (KGK, VR, IPT) extracted independently data concerning study design, main characteristics of included populations, and data regarding primary endpoint from included studies where available. The risk of bias was assessed in terms of patients' selection (selection bias), methodology, analysis and confounders, using a combination of questions from the Quality Assessment of Diagnostic Accuracy Studies (QUADAS-2) and Critical Appraisal Skills Programme (CASP) checklists for assessing cohort studies $(14,15)$. Studies fulfilling $\geq 6$ of the quality domains were deemed as high quality (low risk of bias).

Statistical analysis. For the analysis of the raw data, the Kolmogorov-Smirnov test was used to check the normal distribution of the study variables. Wilcoxon signed-rank test was used to compare $\mathrm{PO}_{2} / \mathrm{FiO}_{2}$ values before and after prone positioning. MannWhitney test was used for comparison between groups i.e., males $v s$. females, awake $v s$. intubated patients. Spearman correlations coefficients ( $r$ ) were determined for assessing the associations of the 


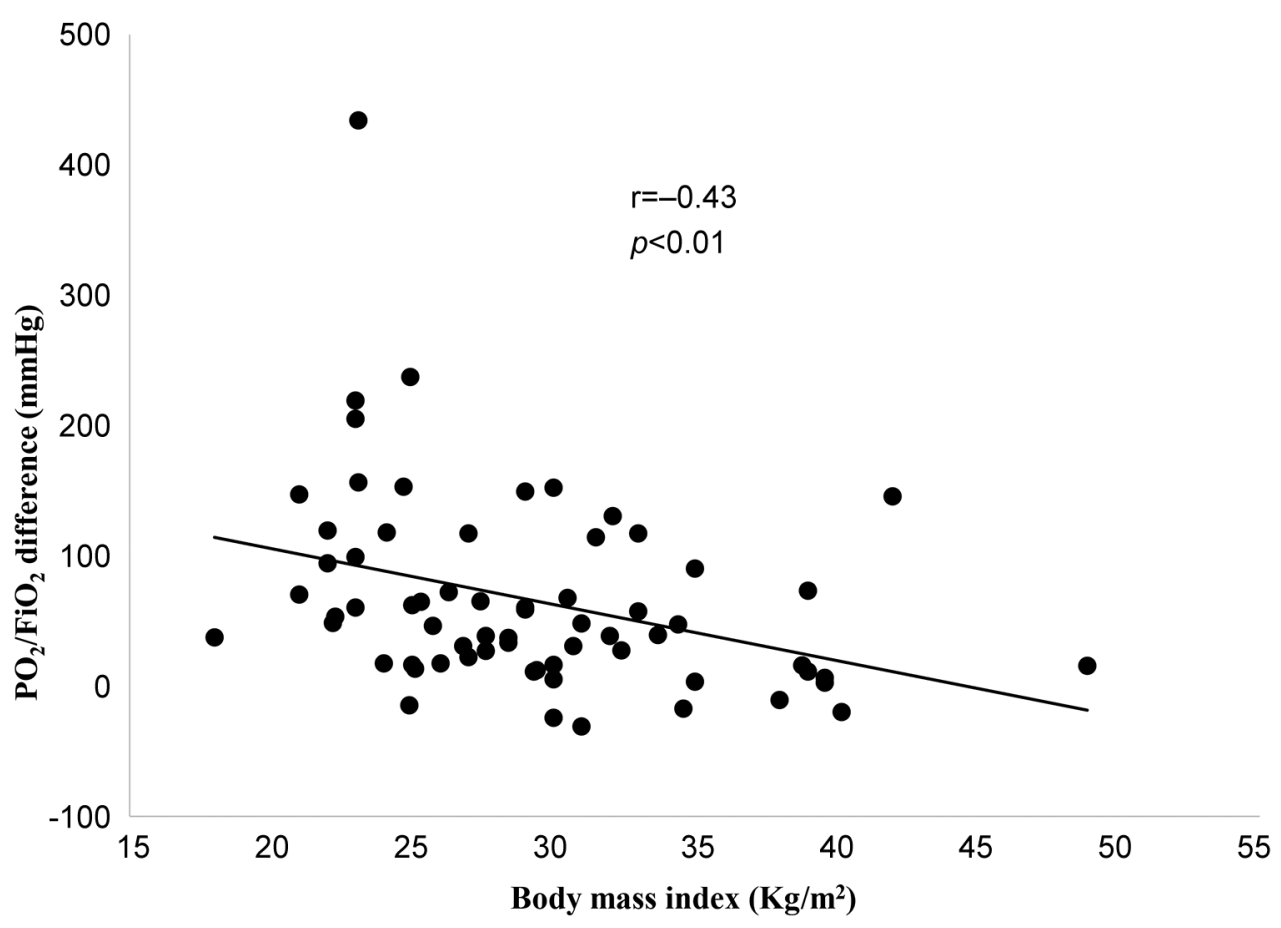

Figure 1. Correlation between post- minus pre-prone $\mathrm{PO}_{2} / \mathrm{FiO}_{2}$ difference and body mass index.

$\mathrm{PO}_{2} / \mathrm{FiO}_{2}$ values. Repeated measures analysis of variance with Bonferroni correction was performed for comparison of $\mathrm{PO}_{2} / \mathrm{FiO}_{2}$ values at different time points in the subgroup with 2 different sessions of pre- versus post-prone assessment. The IBM SPSS Statistics 21 (SPSS Inc., Chicago, IL, USA) statistical package was used. Results are expressed as mean \pm SD.

Random-effects meta-analysis was performed using the Stata/SE 11 (Texas) software. Sensitivity analyses were performed to compensate for the observed methodological heterogeneity among the included studies. Meta-regression analysis was performed for assessing associations of the difference in $\mathrm{PO}_{2} / \mathrm{FiO}_{2}$ values with gender, age, body mass index (BMI), duration of prone positioning and baseline $\mathrm{PO}_{2} / \mathrm{FiO}_{2}$ values. Mean values of subgroups were combined where feasible (16). Median (interquartile range) values were converted to mean values (SD) using appropriate formulas (17). In the case of missing values regarding the mean (SD) of difference in the outcome of interest between the examined groups, these were calculated from the groups' mean values using an appropriate formula for the calculation of the SD of difference as follows:

$$
\mathrm{SD} \text { of difference }=\sqrt{S D_{1}^{2}+S D_{2}^{2}+2 r S D_{1} S D_{2}}
$$

$\mathrm{SD}_{1}$, SD of pre-prone positioning $\mathrm{PO}_{2} / \mathrm{FiO}_{2} ; \mathrm{SD}_{2}$, SD of postprone positioning $\mathrm{PO}_{2} / \mathrm{FiO}_{2} ; \mathrm{r}$, correlation coefficient between preprone and post-prone positioning $\mathrm{PO}_{2} / \mathrm{FiO}_{2}$ as calculated from the raw database (18). Heterogeneity was tested using $\mathrm{I}^{2}$ statistics. Publication bias was assessed by inspecting funnel plots, as well as Egger's test (linear regression method) and Begg's test (rank correlation method) $(19,20)$. Two-sided $p$-values of $<0.05$ were considered statistically significant.

\section{Results}

Analysis of raw data. The methodology and characteristics of the studies contributing to the raw database are shown in Table I (7-12). The database included 121 patients (mean age $59.1 \pm 10.7$ years, $55 \%$ males, $57 \%$ intubated). The mean postversus pre- prone positioning $\mathrm{PO}_{2} / \mathrm{FiO}_{2}$ difference $\pm \mathrm{SD}$ was $50.4 \pm 64.3 \mathrm{mmHg}, p<0.01$ and the mean $\%$ increase in $\mathrm{PO}_{2} / \mathrm{FiO}_{2}$ was $41.7 \pm 58.9 \%$. The $\mathrm{PO}_{2} / \mathrm{FiO}_{2}$ absolute difference and $\%$ change in patients in the awake status $(n=52)$ did not differ compared to that in the intubated patients $(n=69)$ : $58.7 \pm 72.1$ vs. $44.1 \pm 57.5 \mathrm{mmHg}$ and $46.2 \pm 72.0 v s$. $38.4 \pm 47.1 \%$ respectively, $p=\mathrm{NS}$ for both comparisons. Among the 121 patients, a total of 11 (9\%) did not present any increase in $\mathrm{PO}_{2} / \mathrm{FiO}_{2}$ with prone positioning and additional $11(9 \%)$ showed $<10 \%$ increase in $\mathrm{PO}_{2} / \mathrm{FiO}_{2}$.

The increase in $\mathrm{PO}_{2} / \mathrm{FiO}_{2}$ with prone positioning was inversely correlated with BMI ( $\mathrm{r}=-0.43, p<0.01 ; \mathrm{n}=66$ ) (Figure 1), whereas there was no association with age $(\mathrm{r}=-0.07, p=\mathrm{NS})$. The increase in $\mathrm{PO}_{2} / \mathrm{FiO}_{2}$ with prone positioning tended to correlate with baseline pre-prone $\mathrm{PO}_{2} / \mathrm{FiO}_{2}$ values $(\mathrm{r}=0.17, p=0.06)$. There was no difference with respect to gender $(55.5 \pm 71.3 \mathrm{vs} .60 .2 \pm 50.3 \mathrm{mmHg}$ in males $v s$. females respectively, $p=\mathrm{NS}$ ). In 37 patients (24 in the awake status), there was assessment of the $\mathrm{PO}_{2} / \mathrm{FiO}_{2}$ difference in at least 2 separate subsequent sessions or at 


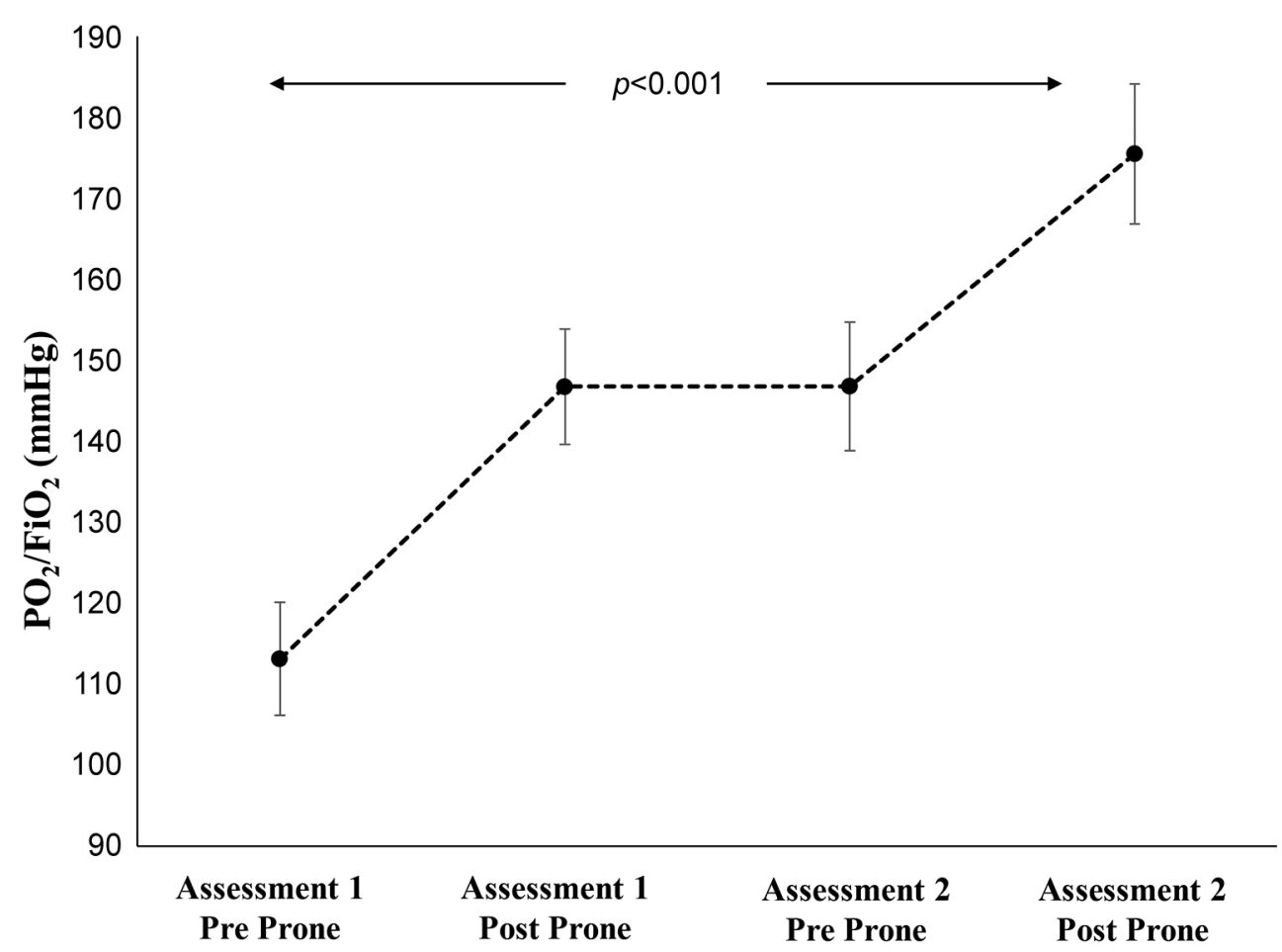

Figure 2. Effect of repeated prone positioning sessions on $\mathrm{PO}_{2} / \mathrm{FiO}_{2}$ values.

least 2 separate days. The effect of repeated prone positioning sessions on $\mathrm{PO}_{2} / \mathrm{FiO}_{2}$ values is shown in Figure 2.

Meta-analysis of aggregate data. Among 836 initially identified articles, 23 studies fulfilled the inclusion criteria and were included in the systematic review (flowchart shown in Figure 3) (7-12, 21-37). The main characteristics of these studies are shown in Table I. Only 10 out of 23 studies reported the time in prone position before $\mathrm{PO}_{2} / \mathrm{FiO}_{2}$ assessment (Table I), whereas the majority of the studies did not report details of the prone positioning protocol (number of cycles/day, hours per cycle, number of days).

Meta-analysis of 23 studies $(n=547$, weighted age $58.3 \pm 4.1,59 \%$ intubated, $73 \%$ males) showed a pooled $\mathrm{PO}_{2} / \mathrm{FiO}_{2}$ difference of 61.8 [95\% confidence intervals $(\mathrm{CI})=49.9-73.6] \mathrm{mmHg}$ (Figure 4).

Egger's test and Begg's funnel plot revealed a small study effect $(p<0.01)$. Nine studies $(33 \%)$ were deemed as low risk of bias $(7,10,12,22-24,28,29,34)$.

Meta-regression analysis did not reveal any significant association of the $\mathrm{PO}_{2} / \mathrm{FiO}_{2}$ difference with mean age, mean $\mathrm{BMI}$, prevalence of males, hypertension, diabetes across studies, the time in prone position before assessment, as well as the risk of bias score of the included studies (all
$p=\mathrm{NS})$. However, there was a trend towards higher $\mathrm{PO}_{2} / \mathrm{FiO}_{2}$ difference in patients with higher pre-prone baseline $\mathrm{PO}_{2} / \mathrm{FiO}_{2}$ values, but this did not reach statistical significance.

In sensitivity analysis including only studies in awake patients ( 11 studies; $\mathrm{n}=227$ ), the pooled $\mathrm{PO}_{2} / \mathrm{FiO}_{2}$ difference was $40.0(95 \% \mathrm{CI}=30.5-49.5) \mathrm{mmHg}$, whereas the respective estimate in studies in intubated patients (12 studies; $\mathrm{n}=320$ ) was $77.4(95 \% \mathrm{CI}=53.4-101.5) \mathrm{mmHg}$.

Regarding feasibility, the percentage of patients unable to retain the prone positioning sessions was reported to be from $0 \%$ to $16 \%(23,29,31,33,34)$. In terms of complications, a single study reported pressure ulcers (stage I or II) in $21 \%$ of intubated patients, which did not compromise further positional care, whereas there were no inadvertent extubations or disruptions of arterial lines, central venous catheters, chest tubes or dialysis catheters (7).

A total of five studies reported the adjusted risk (odds or hazard ratio) for intubation and/or mortality in patients subjected to prone positioning sessions versus those who were not (38-42) (Table II). Due to the heterogeneity in the assessment of the risk estimate and the outcome, as well as the restricted size of data, a meta-analysis was not feasible. However, a trend for a lower adjusted risk could be observed for adverse outcome with prone positioning. 


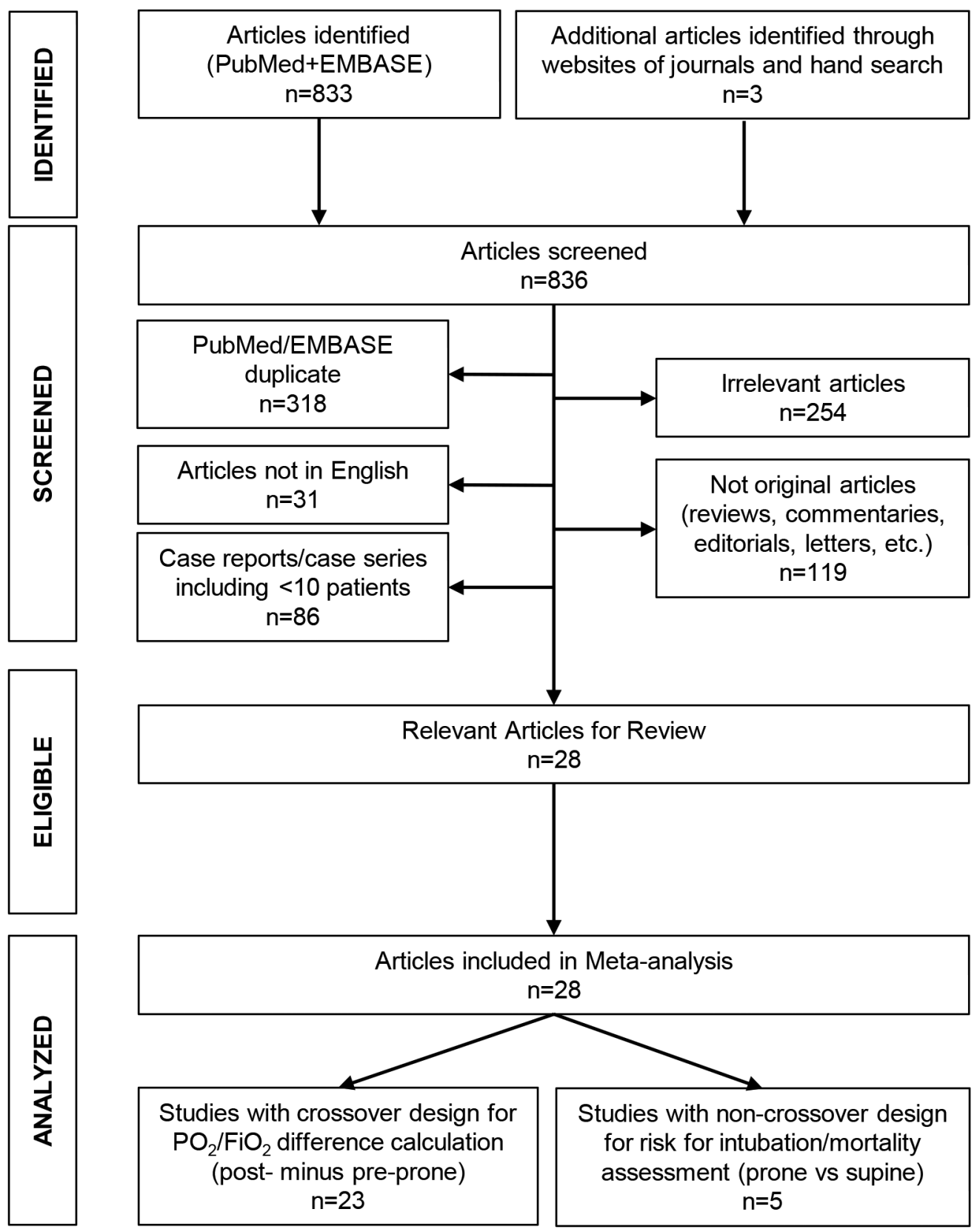

Figure 3. Flow chart for the selection of included studies.

\section{Discussion}

The main findings of the present study included the following: (i) there was a significant improvement in the $\mathrm{PO}_{2} / \mathrm{FiO}_{2}$ after proning in both the awake and intubated patients with COVID-19, consistently evident in the metaanalysis of raw individual data, as well as of aggregate data, (ii) the beneficial effect of prone positioning might be more evident with higher baseline pre-prone $\mathrm{PO}_{2} / \mathrm{FiO}_{2}$ values and lower BMI values, (iii) there was sustained beneficial effect on oxygenation with repeated sessions of prone positioning.

The present meta-analysis of both individual participants' data and aggregate data showed that prone positioning in patients with COVID-19 was associated with an increase in $\mathrm{PO}_{2} / \mathrm{FiO}_{2}$ in the range of $50-60 \mathrm{mmHg}$. The latter regarded patients in the awake status receiving heterogeneous types of oxygen supplementation, as well as mechanically ventilated patients in the Intensive Care Unit. The consistency of the 


\section{Study $\quad \mathrm{PO}_{2} / \mathrm{FiO}_{2}$ difference (mmHg) $(95 \% \mathrm{CI})$ Weight (\%)}

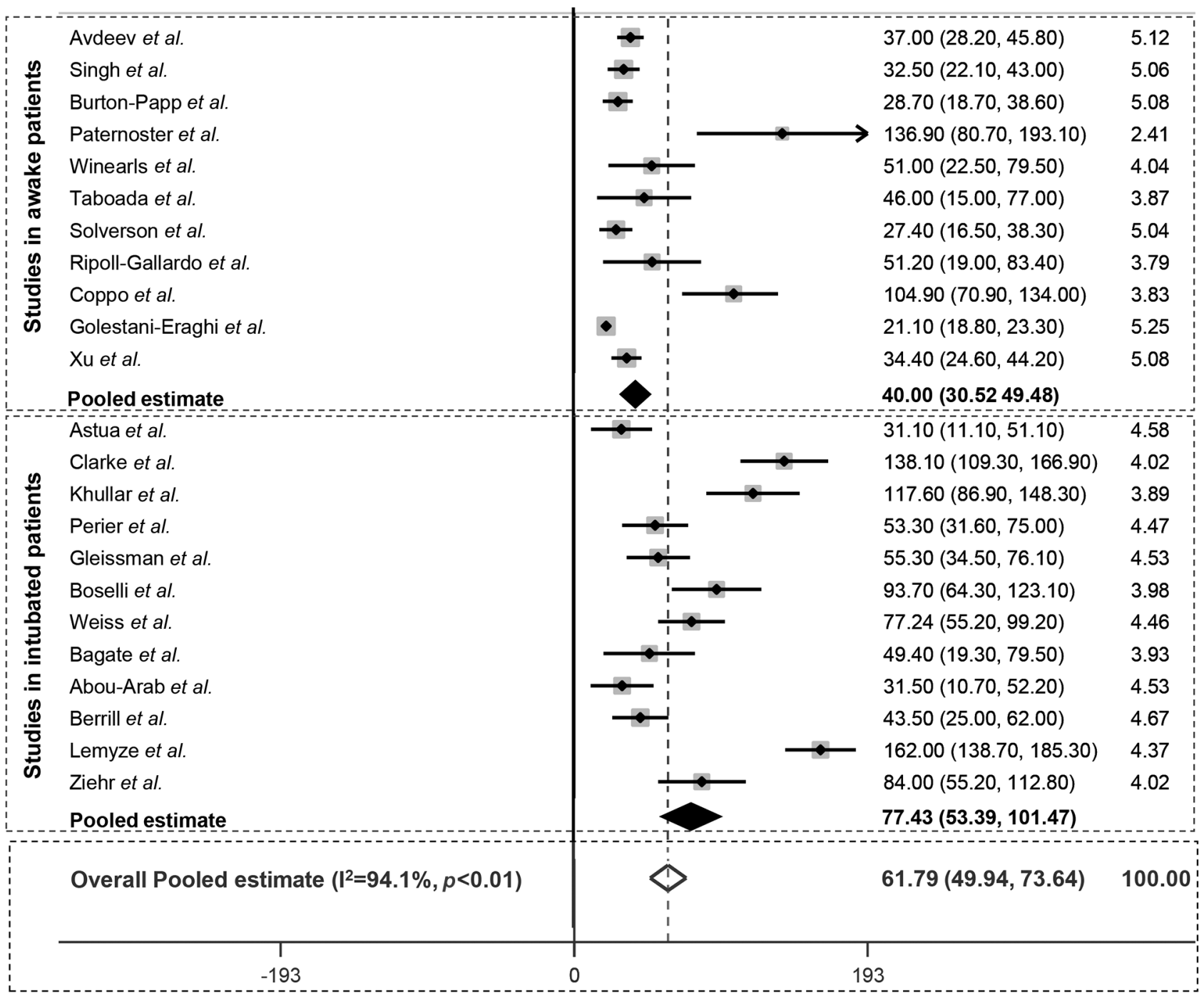

Figure 4. Forest plot of post- minus pre-prone $\mathrm{PO}_{2} / \mathrm{FiO}_{2}$ differences.

above findings across patients with critical COVID-19, but with different types and stages of disease evolution and under different ventilation strategies, confirms the concept of the wide implementation of prone positioning in the management of such patients, especially those in the awake status. In this analysis, about $20 \%$ of patients did not respond or showed $<10 \%$ increase in $\mathrm{PO}_{2} / \mathrm{FiO}_{2}$, which means that not all patients might be responders. Ideally, the phenotype of pneumonia, best identified by a computed tomography scan, could indicate the lung recruitability and potential response (43). The available evidence regarding the effect of prone positioning lacks details about the association of response with pneumonia types, but suggests that prone positioning might be helpful in most patients receiving different types of ventilation. Most importantly, the beneficial effect on oxygenation might be evident after just a few hours. Thus, candidate patients can be selected after just a short-term trial of prone positioning.

Several mechanisms have been proposed for the beneficial effects of prone positioning. The improvement in the ventilation-perfusion disorder (V/Q mismatch), as well as in several oxygenation indicators, ensure a more homogeneous ventilation of alveoli sites and reduce transpulmonary pressures and intra-pulmonary shunt (44). On the other hand, the reported feasibility rates seem to be high (7-12, 21-37) and contraindications are only few including spinal instability, chest tubes, shock, hemodynamic instability, cardiac abnormalities and arrhythmias, burns and wounds, raised intracranial pressure, and pregnancy $(2,45)$. 
The present analysis of raw data showed a trend for an association between the increase in $\mathrm{PO}_{2} / \mathrm{FiO}_{2}$ and baseline preprone $\mathrm{PO}_{2} / \mathrm{FiO}_{2}$ values, as well as an inverse association with BMI. Moreover, repeated sessions of prone positioning appeared to be associated with a sustained or even additional effect on oxygenation. The better response in patients with higher baseline $\mathrm{PO}_{2} / \mathrm{FiO}_{2}$ values could indicate the higher potential of these patients for alveolar recruitment in the early stages of the disease. On the other hand, higher BMI values were associated with a worse response. Whether this finding represents a worse response of the obese patients to prone positioning due to increased intra-abdominal pressure transmitted across the diaphragm, a worse feasibility rate of prone positioning sessions, or a chance finding is not clear and requires further research. Current literature seems to be inconclusive, showing that depending on the mechanics used, proning maneuvers have the potential to induce intra-abdominal hypertension, which can adversely influence the respiratory outcomes (46). It should be mentioned that meta-regression analysis did not confirm the inverse relationship between the increase in $\mathrm{PO}_{2} / \mathrm{FiO}_{2}$ with prone positioning and BMI; yet meta-regression examines the associations between outcome and characteristics, which are aggregate and summarized at the level of the study that in turn can introduce ecological bias.

Despite the evidence in favor of the prone positioning on oxygenation, there were no sufficient data regarding the benefit in terms of outcome. In fact, the available evidence is scarce, although a trend for a slight decrease in the risk for intubation or death was evident. Future randomized studies are warranted to investigate this topic.

The findings of this meta-analysis should be interpreted by considering several limitations. Most important is the heterogeneity among these studies and the lack of details regarding the prone positioning schedule (duration and frequency of prone positioning sessions). Moreover, the main source of evidence is derived from restricted-sized studies, either of retrospective or prospective design. Yet, the metaanalysis of both raw and aggregate data allowed larger sample sizes to be analyzed. However, a small study effect was evident, implying publication bias.

The added value of the present meta-analysis lies on the (i) analysis of both raw (the largest so far database with peerreviewed data) and aggregate data, and (ii) use of strict methodological criteria (only crossover studies) and sensitivity analyses performed separately in awake and intubated patients. Two relevant meta-analyses were recently published presenting consistent findings $(47,48)$. However, these analyses included studies only in awake patients, as well as both peer-reviewed and non-peer-reviewed studies or studies employing either crossover or parallel arm design $(47,48)$. The latter constitutes a criterion with high clinical relevance since in crossover studies each patient serves as a control of her/his own.

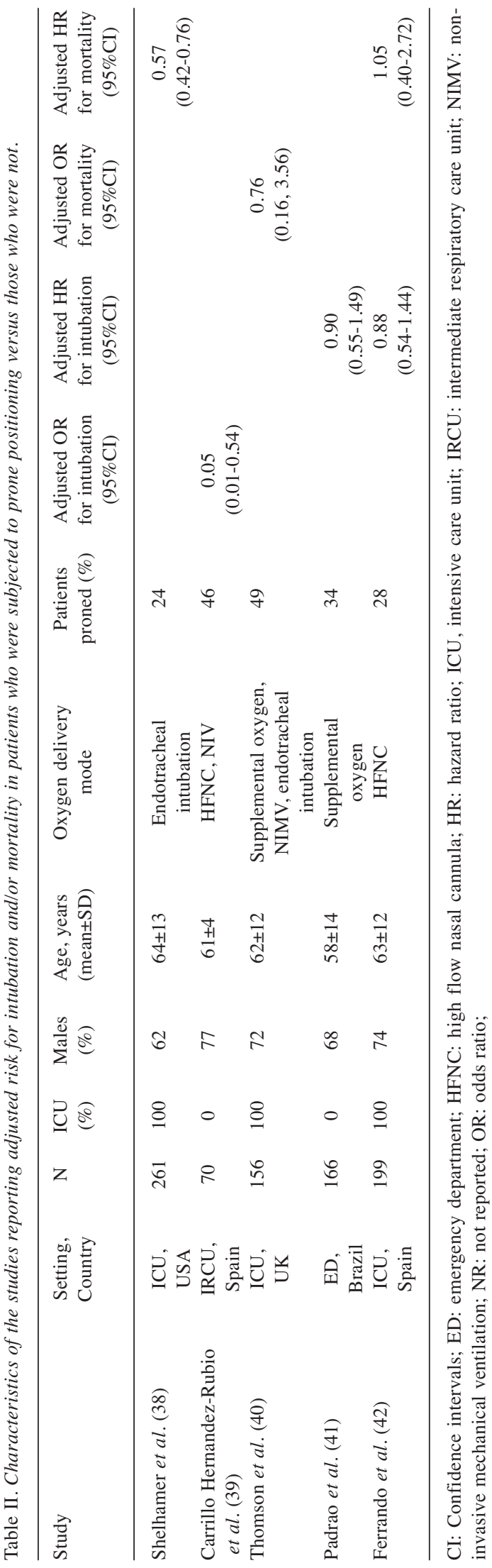


Accumulating evidence suggests a beneficial effect of prone positioning on oxygenation in patients with critical COVID19, either in the awake or the intubated status, and under heterogeneous conditions in terms of ventilation support and prone positioning protocols. Many important details are missing and future well-designed studies should address the following issues: (i) optimal prone positioning protocol (duration and frequency of cycles) and optimal type of delivery (type of beds, type of central lines used, types of oxygen delivery); (ii) type of patients who are more likely to benefit from this (body phenotype, comorbidities, lung phenotype); (iii) whether prone positioning improves the outcome of intubation (in the awake patients), as well as death.

\section{Conflicts of Interest}

The Authors declare no competing interests in relation to this study.

\section{Authors' Contributions}

Conceptualization, A.K. and G.P.; Methodology, A.K., K.G.K., V.R., I.P.T., K.S., G.P. and PROPCOR Consortium-7 Investigators (O.AA., B.A., A.J.A., K.A., F.B-A., D.B., C.B., E.B., A.D., L.G., P.J., E.K. S.K., S.L., W.L., A.J.M., E.K.M., A.R-G., P.S., T.W., Q.X.); Software, A.K., K.G.K., V.R. and I.P.T.; Formal Analysis, A.K. and K.G.K.; Investigation, A.K., K.G.K., V.R., I.P.T. and T.N.; Resources, A.K., K.G.K., V.R., I.P.T., T.N., K.S., G.P., and PROPCOR Consortium-7 Investigators (O.A-A., B.A., A.J.A., K.A., F.B-A., D.B., C.B., E.B., A.D., L.G., P.J., E.K. S.K., S.L., W.L., A.J.M., E.K.M., A.R-G., P.S., T.W., Q.X.); Data Curation, K.G.K., V.R., I.P.T. and PROPCOR Consortium-7 Investigators (O.A-A., B.A., A.J.A., K.A., F.B-A., D.B., C.B., E.B., A.D., L.G., P.J., E.K. S.K., S.L., W.L., A.J.M., E.K.M., A.R-G., P.S., T.W., Q.X.); Writing - Original Draft Preparation, A.K., K.G.K. and T.N.; Writing Review \& Editing, K.S., G.P. and PROPCOR Consortium-7 Investigators (O.A-A., B.A., A.J.A., K.A., F.B-A., D.B., C.B., E.B., A.D., L.G., P.J., E.K. S.K., S.L., W.L., A.J.M., E.K.M., A.R-G., P.S., T.W., Q.X.); Visualization, A.K. and K.G.K.; Supervision, A.K., K.S. and G.P.; Project Administration, A.K., K.G.K., K.S. and G.P.

\section{Acknowledgements}

Data from Xu et al. (doi: 10.1186/s13054-020-02991-7) are included from a study, which was supported, in part, by the Anhui Provincial Special Project of Central Government Guiding Local Science and Technology Development of China (201907d07050001) and the special fund for coronavirus disease 2019 of Wuhu (no. 2020dx2-1 and 2020dx2-2).

\section{References}

1 Pelosi P, Tubiolo D, Mascheroni D, Vicardi P, Crotti S, Valenza $\mathrm{F}$ and Gattinoni L: Effects of the prone position on respiratory mechanics and gas exchange during acute lung injury. Am J Respir Crit Care Med 157(2): 387-393, 1998. PMID: 9476848. DOI: $10.1164 /$ ajrccm.157.2.97-04023

2 Guérin C, Reignier J, Richard JC, Beuret P, Gacouin A, Boulain $\mathrm{T}$, Mercier E, Badet M, Mercat A, Baudin O, Clavel M,
Chatellier D, Jaber S, Rosselli S, Mancebo J, Sirodot M, Hilbert G, Bengler C, Richecoeur J, Gainnier M, Bayle F, Bourdin G, Leray V, Girard R, Baboi L, Ayzac L and PROSEVA Study Group: Prone positioning in severe acute respiratory distress syndrome. N Engl J Med 368(23): 2159-2168, 2013. PMID: 23688302. DOI: 10.1056/NEJMoa1214103

3 Munshi L, Del Sorbo L, Adhikari NKJ, Hodgson CL, Wunsch H, Meade MO, Uleryk E, Mancebo J, Pesenti A, Ranieri VM and Fan E: Prone position for acute respiratory distress syndrome. A systematic review and meta-analysis. Ann Am Thorac Soc 14(Supplement_4): S280-S288, 2017. PMID: 29068269. DOI: 10.1513/AnnalsATS.201704-343OT

4 Armstrong RA, Kane AD, Kursumovic E, Oglesby FC and Cook TM: Mortality in patients admitted to intensive care with COVID-19: an updated systematic review and meta-analysis of observational studies. Anaesthesia 76(4): 537-548, 2021. PMID: 33525063. DOI: $10.1111 /$ anae. 15425

5 Qadri SK, Ng P, Toh TSW, Loh SW, Tan HL, Lin CB, Fan E and Lee JH: Critically ill patients with COVID-19: A narrative review on prone position. Pulm Ther 6(2): 233-246, 2020. PMID: 33085052. DOI: 10.1007/s41030-020-00135-4

6 Weatherald J, Solverson K, Zuege DJ, Loroff N, Fiest KM and Parhar KKS: Awake prone positioning for COVID-19 hypoxemic respiratory failure: A rapid review. J Crit Care 61: 63-70, 2021. PMID: 33096347. DOI: 10.1016/j.jcrc.2020.08.018

7 Astua AJ, Michaels EK and Michaels AJ: Prone during pandemic: development and implementation of a quality-based protocol for proning severe COVID-19 hypoxic lung failure patients in situationally or historically low resource hospitals. BMC Pulm Med 21(1): 25, 2021. PMID: 33435944. DOI: 10.1186/s12890-021-01401-0

8 Singh P, Jain P and Deewan H: Awake prone positioning in COVID-19 patients. Indian J Crit Care Med 24(10): 914-918, 2020. PMID: 33281314. DOI: 10.5005/jp-journals-10071-23546

9 Boselli E, Fatah A, Ledochowski S and Allaouchiche B: ANI and BIS variations in supine and prone position during closed-tracheal suction in sedated and myorelaxed ICU patients with severe COVID-19: A retrospective study. J Clin Monit Comput: 1-7, 2020. PMID: 33159268. DOI: 10.1007/s10877-020-00612-w

10 Abou-Arab O, Haye G, Beyls C, Huette P, Roger PA, Guilbart M, Bernasinski M, Besserve P, Trojette F, Dupont H, Jounieaux $\mathrm{V}$ and Mahjoub $\mathrm{Y}$ : Hypoxemia and prone position in mechanically ventilated COVID-19 patients: a prospective cohort study. Can J Anaesth 68(2): 262-263, 2021. PMID: 33146886. DOI: $10.1007 / \mathrm{s} 12630-020-01844-9$

11 Ripoll-Gallardo A, Grillenzoni L, Bollon J, Della Corte F and Barone-Adesi F: Prone positioning in non-intubated patients with COVID-19 outside of the intensive care unit: More evidence needed. Disaster Med Public Health Prep 14(4): e22e24, 2020. PMID: 32713387. DOI: 10.1017/dmp.2020.267

12 Xu Q, Wang T, Qin X, Jie Y, Zha L and Lu W: Early awake prone position combined with high-flow nasal oxygen therapy in severe COVID-19: a case series. Crit Care 24(1): 250, 2020. PMID: 32448330. DOI: 10.1186/s13054-020-02991-7

13 Liberati A, Altman DG, Tetzlaff J, Mulrow C, Gøtzsche PC, Ioannidis JP, Clarke M, Devereaux PJ, Kleijnen J and Moher D: The PRISMA statement for reporting systematic reviews and meta-analyses of studies that evaluate healthcare interventions: explanation and elaboration. BMJ 339: b2700, 2009. PMID: 19622552. DOI: 10.1136/bmj.b2700 
14 Whiting PF, Rutjes AW, Westwood ME, Mallett S, Deeks JJ, Reitsma JB, Leeflang MM, Sterne JA, Bossuyt PM and QUADAS-2 Group: QUADAS-2: a revised tool for the quality assessment of diagnostic accuracy studies. Ann Intern Med 155(8): 529-536, 2011. PMID: 22007046. DOI: 10.7326/00034819-155-8-201110180-00009

15 Critical Appraisal Skills Programme (CASP): Cohort Study Checklist. Available at: https://casp-uk.net/casp-tools-checklists [Last accessed on October 21, 2021]

16 StatsToDo: Combine Means and SDs Into One Group Program. Available at: https://www.statstodo.com/CombineMeansSDs.php [Last accessed on October 21, 2021]

17 Wan X, Wang W, Liu J and Tong T: Estimating the sample mean and standard deviation from the sample size, median, range and/or interquartile range. BMC Med Res Methodol 14: 135, 2014. PMID: 25524443. DOI: 10.1186/1471-2288-14-135

18 Arifin W: Calculating standard deviation of difference for determination of sample size for planned paired $t$-test analysis. Educ Med 6(2), 2014. DOI: 10.5959/eimj.v6i2.252

19 Begg CB and Mazumdar M: Operating characteristics of a rank correlation test for publication bias. Biometrics 50(4): 10881101, 1994. PMID: 7786990.

20 Egger M, Davey Smith G, Schneider M and Minder C: Bias in meta-analysis detected by a simple, graphical test. BMJ 315(7109): 629-634, 1997. PMID: 9310563. DOI: 10.1136/ bmj.315.7109.629

21 Avdeev SN, Nekludova GV, Trushenko NV, Tsareva NA, Yaroshetskiy AI and Kosanovic D: Lung ultrasound can predict response to the prone position in awake non-intubated patients with COVID 19 associated acute respiratory distress syndrome. Crit Care 25(1): 35, 2021. PMID: 33494771. DOI: 10.1186/ s13054-021-03472-1

22 Clarke J, Geoghegan P, McEvoy N, Boylan M, Ní Choileáin O, Mulligan M, Hogan G, Keogh A, McElvaney OJ, McElvaney OF, Bourke J, McNicholas B, Laffey JG, McElvaney NG and Curley GF: Prone positioning improves oxygenation and lung recruitment in patients with SARS-CoV-2 acute respiratory distress syndrome; a single centre cohort study of 20 consecutive patients. BMC Res Notes 14(1): 20, 2021. PMID: 33422143. DOI: $10.1186 / \mathrm{s} 13104-020-05426-2$

23 Khullar R, Shah S, Singh G, Bae J, Gattu R, Jain S, Green J, Anandarangam T, Cohen M, Madan N and Prasanna P: Effects of prone ventilation on oxygenation, inflammation, and lung infiltrates in COVID-19 related acute respiratory distress syndrome: A retrospective cohort study. J Clin Med 9(12): 4129, 2020. PMID: 33371426. DOI: 10.3390/jcm9124129

24 Perier F, Tuffet S, Maraffi T, Alcala G, Victor M, Haudebourg AF, Razazi K, De Prost N, Amato M, Carteaux G and Mekontso Dessap A: Electrical impedance tomography to titrate positive end-expiratory pressure in COVID-19 acute respiratory distress syndrome. Crit Care 24(1): 678, 2020. PMID: 33287864. DOI: 10.1186/s13054-020-03414-3

25 Gleissman H, Forsgren A, Andersson E, Lindqvist E, Lipka Falck A, Cronhjort M, Dahlberg $\mathrm{M}$ and Günther M: Prone positioning in mechanically ventilated patients with severe acute respiratory distress syndrome and coronavirus disease 2019. Acta Anaesthesiol Scand 65(3): 360-363, 2021. PMID: 33165936. DOI: $10.1111 /$ aas.13741

26 Weiss TT, Cerda F, Scott JB, Kaur R, Sungurlu S, Mirza SH, Alolaiwat AA, Kaur R, Augustynovich AE and Li J: Prone positioning for patients intubated for severe acute respiratory distress syndrome (ARDS) secondary to COVID-19: a retrospective observational cohort study. Br J Anaesth 126(1): 48-55, 2021. PMID: 33158500. DOI: 10.1016/j.bja.2020.09.042

27 Bagate F, Tuffet S, Masi P, Perier F, Razazi K, de Prost N, Carteaux G, Payen D and Mekontso Dessap A: Rescue therapy with inhaled nitric oxide and almitrine in COVID-19 patients with severe acute respiratory distress syndrome. Ann Intensive Care 10(1): 151, 2020. PMID: 33150525. DOI: 10.1186/s13613020-00769-2

28 Burton-Papp HC, Jackson AIR, Beecham R, Ferrari M, NasimMohi M, Grocott MPW, Chambers R, Dushianthan A, University Hospital Southampton Critical Care Team and REACT COVID Investigators: Conscious prone positioning during non-invasive ventilation in COVID-19 patients: experience from a single centre. F1000Res 9: 859, 2020. PMID: 33110499. DOI: 10.12688/f1000research.25384.1

29 Paternoster G, Sartini C, Pennacchio E, Lisanti F, Landoni G and Cabrini L: Awake pronation with helmet continuous positive airway pressure for COVID-19 acute respiratory distress syndrome patients outside the ICU: A case series. Med Intensiva (Engl Ed), 2020. PMID: 33067029. DOI: 10.1016/j.medin. 2020.08.008

30 Berrill M: Evaluation of oxygenation in 129 proning sessions in 34 mechanically ventilated COVID-19 patients. J Intensive Care Med 36(2): 229-232, 2021. PMID: 32993451. DOI: 10.1177/ 0885066620955137

31 Winearls S, Swingwood EL, Hardaker CL, Smith AM, Easton FM, Millington KJ, Hall RS, Smith A and Curtis KJ: Early conscious prone positioning in patients with COVID-19 receiving continuous positive airway pressure: a retrospective analysis. BMJ Open Respir Res 7(1): e000711, 2020. PMID: 32895247. DOI: 10.1136/bmjresp-2020-000711

32 Taboada M, Rodríguez N, Riveiro V, Baluja A and Atanassoff PG: Prone positioning in awake non-ICU patients with ARDS caused by COVID-19. Anaesth Crit Care Pain Med 39(5): 581583, 2020. PMID: 32828956. DOI: 10.1016/j.accpm.2020.08.002

33 Solverson K, Weatherald J and Parhar KKS: Tolerability and safety of awake prone positioning COVID-19 patients with severe hypoxemic respiratory failure. Can J Anaesth 68(1): 6470, 2021. PMID: 32803468. DOI: 10.1007/s12630-020-01787-1

34 Coppo A, Bellani G, Winterton D, Di Pierro M, Soria A, Faverio P, Cairo M, Mori S, Messinesi G, Contro E, Bonfanti P, Benini A, Valsecchi MG, Antolini L and Foti G: Feasibility and physiological effects of prone positioning in non-intubated patients with acute respiratory failure due to COVID-19 (PRONCOVID): a prospective cohort study. Lancet Respir Med 8(8): 765-774, 2020. PMID: 32569585. DOI: 10.1016/S22132600(20)30268-X

35 Golestani-Eraghi M and Mahmoodpoor A: Early application of prone position for management of Covid-19 patients. J Clin Anesth 66: 109917, 2020. PMID: 32473503. DOI: 10.1016/ j.jclinane.2020.109917

36 Lemyze M, Courageux N, Maladobry T, Arumadura C, Pauquet P, Orfi A, Komorowski M, Mallat J and Granier M: Implications of obesity for the management of severe Coronavirus disease 2019 pneumonia. Crit Care Med 48(9): e761-e767, 2020. PMID: 32452889. DOI: 10.1097/CCM.0000000000004455

37 Ziehr DR, Alladina J, Petri CR, Maley JH, Moskowitz A, Medoff BD, Hibbert KA, Thompson BT and Hardin CC: 
Respiratory pathophysiology of mechanically ventilated patient with COVID-19: A cohort study. Am J Respir Crit Care Med 201(12): 1560-1564, 2020. PMID: 32348678. DOI: 10.1164/ rccm.202004-1163LE

38 Shelhamer MC, Wesson PD, Solari IL, Jensen DL, Steele WA, Dimitrov VG, Kelly JD, Aziz S, Gutierrez VP, Vittinghoff E, Chung KK, Menon VP, Ambris HA and Baxi SM: Prone positioning in moderate to severe acute respiratory distress syndrome due to COVID-19: A cohort study and analysis of physiology. J Intensive Care Med 36(2): 241-252, 2021. PMID: 33380236. DOI: $10.1177 / 0885066620980399$

39 Carrillo Hernandez-Rubio J, Sanchez-Carpintero Abad M, Yordi Leon A, Doblare Higuera G, Garcia Rodriguez L, Garcia Torrejon C, Mayor Cacho A, Jimenez Rodriguez A and GarciaSalmones Martin M: Outcomes of an intermediate respiratory care unit in the COVID-19 pandemic. PLoS One 15(12): e0243968, 2020. PMID: 33326484. DOI: 10.1371/journal.pone. 0243968

40 Thomson RJ, Hunter J, Dutton J, Schneider J, Khosravi M, Casement A, Dhadwal K and Martin D: Clinical characteristics and outcomes of critically ill patients with COVID-19 admitted to an intensive care unit in London: A prospective observational cohort study. PLoS One 15(12): e0243710, 2020. PMID: 33320904. DOI: 10.1371/journal.pone.0243710

41 Padrão EMH, Valente FS, Besen BAMP, Rahhal H, Mesquita PS, de Alencar JCG, da Costa MGP, Wanderley APB, Emerenciano DL, Bortoleto FM, Fortes JCL, Marques B, de Souza SFB, Marchini JFM, Neto RAB, de Souza HP and COVIDTEAM: Awake prone positioning in COVID-19 hypoxemic respiratory failure: Exploratory findings in a singlecenter retrospective cohort study. Acad Emerg Med 27(12): 1249-1259, 2020. PMID: 33107664. DOI: 10.1111/acem.14160

42 Ferrando C, Mellado-Artigas R, Gea A, Arruti E, Aldecoa C, Adalia R, Ramasco F, Monedero P, Maseda E, Tamayo G, Hernández-Sanz ML, Mercadal J, Martín-Grande A, Kacmarek RM, Villar J, Suárez-Sipmann F and COVID-19 Spanish ICU Network: Awake prone positioning does not reduce the risk of intubation in COVID-19 treated with high-flow nasal oxygen therapy: a multicenter, adjusted cohort study. Crit Care 24(1): 597, 2020. PMID: 33023669. DOI: 10.1186/s13054-020-03314-6
43 Gattinoni L, Chiumello D, Caironi P, Busana M, Romitti F, Brazzi L and Camporota L: COVID-19 pneumonia: different respiratory treatments for different phenotypes? Intensive Care Med 46(6): 1099-1102, 2020. PMID: 32291463. DOI: 10.1007/ s00134-020-06033-2

44 Telias I, Katira BH and Brochard L: Is the prone position helpful during spontaneous breathing in patients with COVID-19? JAMA 323(22): 2265-2267, 2020. PMID: 32412579. DOI: 10.1001/jama.2020.8539

45 Ryan DW and Pelosi P: The prone position in acute respiratory distress syndrome. BMJ 312(7035): 860-861, 1996. PMID: 8611862. DOI: $10.1136 / \mathrm{bmj} .312 .7035 .860$

46 Kirkpatrick AW, Pelosi P, De Waele JJ, Malbrain ML, Ball CG, Meade MO, Stelfox HT and Laupland KB: Clinical review: Intra-abdominal hypertension: does it influence the physiology of prone ventilation? Crit Care 14(4): 232, 2010. PMID: 20804560. DOI: $10.1186 /$ cc 9099

47 Ponnapa Reddy M, Subramaniam A, Afroz A, Billah B, Lim ZJ, Zubarev A, Blecher G, Tiruvoipati R, Ramanathan K, Wong SN, Brodie D, Fan E and Shekar K: Prone positioning of nonintubated patients with Coronavirus disease 2019-A systematic review and meta-analysis. Crit Care Med 49(10): e1001-e1014, 2021. PMID: 33927120. DOI: 10.1097/ CCM.0000000000005086

$48 \mathrm{~Pb}$ S, Mittal S, Madan K, Mohan A, Tiwari P, Hadda V, Pandey $\mathrm{RM}$ and Guleria R: Awake prone positioning in non-intubated patients for the management of hypoxemia in COVID-19: A systematic review and meta-analysis. Monaldi Arch Chest Dis 91(2), 2021. PMID: 33926179. DOI: 10.4081/monaldi. 2021.1623
Received October 10, 2021

Revised October 20, 2021

Accepted October 22, 2021 